\title{
Anthropometric Evaluation of Nutritional Status of Adolescents Attending the Secondary Schools 1 and 2 of Gagnoa (Côte d'Ivoire)
}

\author{
Yao N'guessan Blaise, \\ N’dia Kouadio Frédéric, \\ Oussou N'guessan Jean-Baptiste, \\ Yapo Angoué Paul, \\ Laboratory of Physiology, Pharmacology and Pharmacopoeia, \\ Nangui Abrogoua University, Abidjan, Côte d'Ivoire
}

Doi: 10.19044/esj.2019.v15n15p323 URL:http://dx.doi.org/10.19044/esj.2019.v15n15p323

\begin{abstract}
This study aims to evaluate the nutritional status of adolescents attending two secondary schools in Gagnoa (Côte d'Ivoire) based on anthropometric parameters. A sample of 184 adolescents was recruited in the secondary schools 1 and 2 of Gagnoa. Measurements of body mass and height were made using a scale and a measuring board equipped with a tape measure respectively. Anthropometric indices (height-for-age Z-score and BMI-forage Z-score) were calculated according to the WHO (2007) growth references for 5-19 years old children. Mean age was $14.9 \pm 0.2$ years, mean body weight was $48.2 \pm 0.7 \mathrm{~kg}$ and mean height was $156.1 \pm 0.7 \mathrm{~cm}$. The results of this study revealed a deficit of $13 \%$ and an underweight of $8.7 \%$. Undernutrition in the population is characterized by $1.6 \%$ severe chronic undernutrition, $11.4 \%$ moderate chronic undernutrition, $8.7 \%$ moderate acute malnutrition and $0.5 \%$ severe acute malnutrition. The prevalence of obesity in this population was $0.5 \%$. The assessment of the nutritional status of the adolescents attending the two secondary schools of Gagnoa has revealed deficiency stature and thinness among students.
\end{abstract}

Keywords: Anthropometry, nutritional status, adolescents, stunting, underweight

\section{Introduction}

Malnutrition is a public health problem. It is expressed in two forms such as overnutrition and undernutrition (Anonymous, 2015). Undernutrition is the most prevalent form of malnutrition in sub-Sub Sahara african countries 
(Garenne, 2014). It includes cases of underweight, stunting, wasting and vitamin and mineral deficiencies (WHO, 2000). These elements reduce physical and intellectual capacities and make men vulnerable to disease (Latham and Cobos, 1971, Singh, 2004).

In developing countries, $16.6 \%$ of childern were considered underweigh and the percentage in Weast Africa was 20.5\% (Anonymous, 2015).

In Côte d'Ivoire, works carried out on children in two southern regions (Agnébi region and Abidjan city) confirmed the existence of underweight and stunting (Yapi et al. 2005, Bléyéré et al., 2013). However, to our knowledge, no studies have been undertaken in the middle west region of Côte d'Ivoire. This study, therefore, aimed at evaluating adolescents' nutritional status and also to establish a relationship between the socio-demographic situation and the nutritional status of adolescents in the secondary schools 1 and 2 in Gagnoa, a town located in the middle west part of Côte d'Ivoire.

\section{Material and Methods Study Area and Subjects}

The survey was done between January and April 2016 at the secondary school 1 and 2 of Gagnoa (Côte d'Ivoire). The study population consists of 184 students (94 girls and 90 boys) aged between 11 and 18 years old. All the subjects were considered apparently in good health by their parents, school managers and the medical team of the Hospital of Gagnoa who accompanied us in this study.

\section{Collection of Data}

\section{Measurement of Anthropometric Indices}

Our investigation is a cross-sectional study in which all the subjects recruited have been subjected to an anthropometric examination (weight, body mass and height). These anthropometric parameters measurement were based on the WHO standard method (WHO, 1983). Body mass was measured using a mechanical weighing scale (CAMRY BR9709, France). The size was measured using a metric tape, locally manufactured, with an accuracy of 0.1 $\mathrm{cm}$. The weight or body mass and height of each subject were monitored in school uniforms (white camisole and blue skirt for girls, pants and khaki shirt for boys) without shoes. The body mass index (BMI) expressed in $\mathrm{kg} / \mathrm{m}^{2}$ was calculated by dividing body weight $(\mathrm{kg})$ by squared height according to the formula used in the works of several authors (Collins and Myatt, 2000; Dorlencourt et al., 2000; Cogill, 2003 and Cole et al., 2007). This index allows to evaluate the nutritional status of the study population. 


\section{BMI $=$ Weight $/(\text { Height })^{2}$}

Sociodemographic information (age, sex, occupation and educational level of the father, size or number of children in the household, and rank in siblings) of each recruited subject were also collected using a prepared survey sheet.

\section{Anthropometric Indices Evaluation}

The indices used for anthropometric assessment of adolescents are height-for-age and BMI-for-age (Cogill, 2003). The Z-score values (or standard deviations) were used for the classification of the statural and weight status of adolescents through the categories of anthropometric indices. The Zscore values for each adolescent were calculated according to the following formulas:

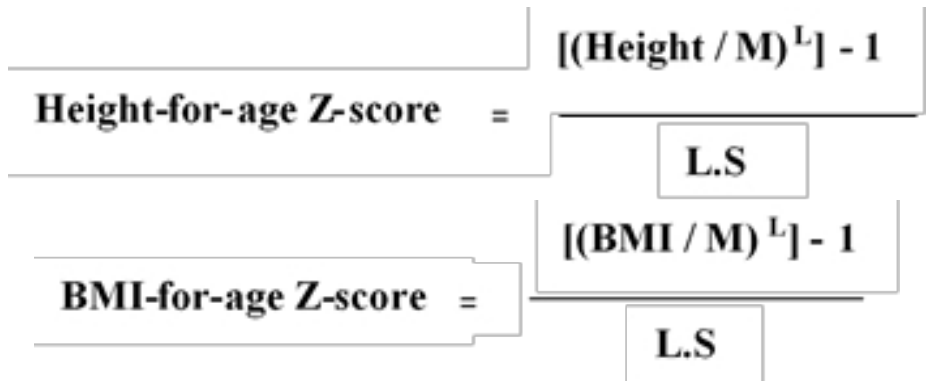

L: expresses the Box-Cox power needed to transform the sample into a normal distribution sample; $\mathbf{M}$ : Median reference population by age; $\mathbf{S}$ : coefficient of variation of BMI (Box and Cox, 1964). The L, M, and S values are provided according to age and sex, respectively, by the 5-to-19-year-old height-for-age (size-for-age Z-score) tables and the BMI-for-age tables age 5 to 19 years (BMI-for-age Z-score) (Butte et al., 2007, Cole et al., 2007, De Onis et al., 2007, Wamba et al., 2013).

The Z-scores were, thus, determined by calculation according to the growth references of the WHO (2007) for 5-19 years (Khadilkar et al., 2009, Flegal and Cole, 2013). The Z-score index compares an adolescent or a group of adolescents in a reference population (Armitage and Berry, 1987, Waterlow, 1992, Rodríguez-López et al., 2010). Different anthropometric indicators have been adopted to determine the different categories of individuals in a population. Thus, subjects with a size-for-age Z-score index $<-2$ SD are under-stature (stunted); the normal size subject is the one whose height-for-age Z-score index $\geq-2 \mathrm{SD}$; underweight (thinness) is reported for the BMI-for-age Z-score index < - 2SD (De Onis et al., 2007); the overweight risk indicator is indicated as a subject with a BMI-for-age Z-score $>+1 \mathrm{SD}$ and subjects with a BMI-for-age Z-score $>+2$ SD are obese (WHO, 1978). 


\section{Statistical Analysis}

The calculation of variables' means and the analysis of all the data were performed using the software $\mathrm{R} X$ 64.3.3.2. All statistical tests were considered significant when $p$-value was less than 0.05 .

\section{Results}

\section{Anthropometric Characteristics of the Study Population}

\section{Anthropometric Measures and Indices of the Study Population}

Table 1 presents the average values of anthropometric measures and indices of subjects. The average age of the study population is $14.9 \pm 0.2$ years. With an average of $14.9 \pm 0.2$ years, the average age of girls is roughly equal to that of boys with an average age of $14.8 \pm 0.4$ years.

The body mass of the study population is $48.2 \pm 0.7 \mathrm{~kg}$. Girls have an average body mass of $50.1 \pm 0.9 \mathrm{~kg}$. This value is higher than that of boys who have an average body mass of $46.2 \pm 1.2 \mathrm{~kg}$. However, the difference is not significant $(p>0.05)$.

At the size level, the average value of the study population is $1.56 \pm$ $0.07 \mathrm{~m}$. With an average height of $1.56 \pm 0.07 \mathrm{~m}$ for girls and $1.56 \pm 0.13 \mathrm{~m}$ for boys. Results showed that the size of both sexes are roughly the same.

As for the body mass index (BMI), the mean value is $19.6 \pm 0.2 \mathrm{~kg} /$ $\mathrm{m}^{2}$ for the entire study population. $20.6 \pm 0.3 \mathrm{~kg} / \mathrm{m}^{2}$ and $19 \pm 0,2 \mathrm{~kg} / \mathrm{m}^{2}$ respectively for girls and boys. The average BMI for girls is higher than that of boys without any significant difference $(p>0.05)$.

For the size-for-age Z-score index, the mean value is $-0.8 \pm 0.1 \mathrm{SD}$ for the total population. This index is lower for boys than for girls. This difference is statistically significant $(p<0.05)$. The mean value of the BMI-for-age Zscore index recorded at the level of the total population is $-0.2 \pm 0.1 \mathrm{SD}$. A significant difference was shown between the two sexes $(p<0.05)$. The mean value of this index is higher among girls $(0.0 \pm 0.1 \mathrm{SD})$ when compared to that of boys $(-0.5 \pm 0.1 \mathrm{SD})$.

\section{Stature and Weight Status of the Adolescents}

Table 2 summarizes the different types of stature and weight status in Gagnoa's secondary school 1 and 2 . In the study population, results shows that $13 \%$ of the adolescents had a short stature while $87 \%$ had a normal one. The difference between these two statural status is significant $(p<0.05)$. Regarding the weight status, $9.2 \%$ of the subjects were underweight against $82.6 \%$ of subjects who have a normal weight. There is a significant difference $(p<0.05)$ between these two weight classes. The proportion of adolescents at risk of being overweight is $7.6 \%$. Within this study population, only one adolescent showed signs of obesity. A significant difference $(p<0.05)$ was recorded between subjects at risk of overweight compared with those of 
normal weight on the one hand, and between obese subjects and subjects of normal weight on the other hand.

Table 1 : Mean values of anthropometric measures and indices

\begin{tabular}{lllll}
\hline Measures and indices & $\begin{array}{l}\text { Total Population } \\
(\mathbf{N = 1 8 4 )}\end{array}$ & $\begin{array}{l}\text { Girls } \\
(\mathbf{N = 9 4 )}\end{array}$ & $\begin{array}{l}\text { Boys } \\
(\mathbf{N = 9 0 )}\end{array}$ & $\boldsymbol{p}$ \\
\hline Age (years old) & $14.9 \pm 0.2$ & $14.9 \pm 0.2$ & $14.8 \pm 0.4$ & $\mathrm{NS}$ \\
Body mass (kg) & $48.2 \pm 0.7$ & $50.1 \pm 0.9$ & $46.2 \pm 1.2$ & $\mathrm{NS}$ \\
Height (m) & $1.56 \pm 0.7$ & $1.56 \pm 0.7$ & $1.56 \pm 1.3$ & $\mathrm{NS}$ \\
BMI $\left(\mathrm{kg} / \mathrm{m}^{2}\right)$ & $19.8 \pm 0.2$ & $20.6 \pm 0.3$ & $19 \pm 0.2$ & $\mathrm{NS}$ \\
\hline Height-for-age Z-Score (SD) & $-0.8 \pm 0.1$ & $-0.5 \pm 0.1$ & $-1.1 \pm 0.1$ & $\mathrm{~S}$ \\
BMI-for-age Z-Score (SD) & $-0.2 \pm 0.1$ & $0.0 \pm 0.1$ & $-0.5 \pm 0.1$ & $\mathrm{~S}$ \\
\hline
\end{tabular}

BMI : Body Mass Index, $\boldsymbol{p}:$ threshold of significance,

NS : Non significant, $\mathbf{S}$ : Significant, SD : Standard deviation

Table 2 : Stature and weight status of the adolescents

\begin{tabular}{|c|c|c|c|c|c|}
\hline \multicolumn{2}{|c|}{ Anthropometric indices } & $\mathbf{n}$ & $\begin{array}{c}\text { Prevalence } \\
(\%)\end{array}$ & $p$ & Stature status \\
\hline $\begin{array}{l}\text { Height- for-age Z- } \\
\text { score }\end{array}$ & $\begin{array}{l}<-2 \mathrm{SD} \\
>-2 \mathrm{SD}\end{array}$ & $\begin{array}{c}24 \\
160\end{array}$ & $\begin{array}{l}13 \\
87\end{array}$ & $\mathrm{~S}$ & $\begin{array}{l}\text { Short stature } \\
\text { Normal stature }\end{array}$ \\
\hline \multirow{4}{*}{ BMI-for-age Z-score } & $<-2 \mathrm{SD}$ & 17 & 9.2 & \multirow[b]{2}{*}{ S } & Under weight \\
\hline & $\begin{array}{c}>-2 \mathrm{SD}< \\
\quad+1 \mathrm{SD}\end{array}$ & 152 & 82.6 & & Normal weight \\
\hline & $>+1 \mathrm{SD}$ & 14 & 7.6 & \multirow[t]{2}{*}{$\mathrm{S}$} & $\begin{array}{c}\text { Risk of } \\
\text { overweight }\end{array}$ \\
\hline & $>+2 \mathrm{SD}$ & 1 & 0.5 & & Obesity \\
\hline
\end{tabular}

BMI : Body Mass Index, $\mathbf{n}$ : Number of cases for each parameter, $\boldsymbol{p}$ : threshold of significance, $\mathbf{S}:$ Significant, SD : Standard Deviation

\section{Stature and Weight Status in Relation to the Adolescents' Gender}

The prevalence of stature deficiency, underweight, overweight risk and obesity in relation to students' sex attending schools are shown in table 3.

Results showed that the prevalence of stature is $8.5 \%$ for girls while that of boys is $17.8 \%$. The prevalence of stature deficiency is higher in boys than Girls. However, the difference is not statistically significant $(p>0.05)$. With regard to the students' weight, results showed that $5.3 \%$ of boys and $13.3 \%$ of girls have lower body mass indexes in relation to their age. There is no significant difference $(p>0.05)$ between the proportion of girls and boys who are underweight. $12.8 \%$ of girls and $2.2 \%$ of boys are at the risk of overweight. A significant difference $(p<0.05)$ is observed between them. As for the presence of obesity in population of both sex, results showed that one girl was obese but no case with boys. 
Table 3 : Prevalences of stature and weight status in relation to the Adolescents' gender

\begin{tabular}{|c|c|c|c|c|c|}
\hline \multirow{2}{*}{$\begin{array}{l}\text { Stature and weight } \\
\text { status }\end{array}$} & \multicolumn{2}{|c|}{ Girls (N = 94) } & \multirow[b]{2}{*}{$p$} & \multicolumn{2}{|c|}{ Boys $(N=90)$} \\
\hline & $\mathbf{n}$ & $\begin{array}{c}\text { Prevalence } \\
(\%)\end{array}$ & & n & $\begin{array}{c}\text { Prevalence } \\
(\%)\end{array}$ \\
\hline Stature deficiency & 8 & 8.5 & NS & 16 & 17.8 \\
\hline Normal stature & 86 & 91.5 & NS & 74 & 82.2 \\
\hline Under weight & 5 & 5.3 & NS & 12 & 13.3 \\
\hline Normal weight & 76 & 80.8 & NS & 76 & 84.4 \\
\hline Risk of overweight & 12 & 12.8 & S & 2 & 2.2 \\
\hline Obesity & 1 & 1.1 & NS & 0 & 0 \\
\hline
\end{tabular}

$\mathbf{N}$ : Total number of adolescents, $\boldsymbol{p}:$ threshold of significance, $\mathrm{n}:$ Number of adolescents showing a statural and weight status, $\mathbf{N S}$ : Non significant, $\mathbf{S}$ : Significant

\section{Nutritional Status of the Study Population}

Different nutritional status classes were recorded with varying proportions within the study population (Table 4). 3.3\% of boys were severe chronically undernourished whereas all of the girls were healthy. Moderate chronic undernutrition had a higher prevalence in boys than girls. In fact, this parameter was $14.4 \%$ for boys and $8.5 \%$ for girls. However, the difference wasn't significant $(p>0.05)$. None of the girls were found to be Severe acutely malnourished meanwhile $1.1 \%$ of boys had this problem.

Results also showed that $12.2 \%$ of boys and $5.3 \%$ of girls had moderate acute malnutrition. This difference was not significant ( $p>0.05$ ). The prevalence of over-nutrition was higher among girls than boys. In fact, the prevalence was $1.1 \%$ among girls and no cases of over-nutrition were encountered in the male population.

\section{Influence of Socio-Demographic Factors on Students' Nutritional Status}

The results of the influences of socio-demographic factors on the nutritional status of the study population were presented in Table 5. Regardless the sociodemographic parameter (students' father education background, professional status of the father, size of the household or rank in siblings), different classes of nutritional status were found in the study population.

With regard to the students' father education background, results showed that most of adolescents have a bad nutritional status groups either their father are educated or not. These bad groups are severe chronic undernutrition, moderate chronic undernutrition, severe acute malnutrition and moderate acute malnutrition.

At the level of the father's professional situation, results, also, showed that adolescents whose father has no fixed income as well as those whose father has a fixed income, have not a good nutritional profile. Thus, 7 chronically undernourished adolescents have their father with no fixed income against 17 adolescents in the same nutritional situation whose father has a 
fixed income, and 13 teenagers whose father has a fixed income out of the 17 subjects showed signs of acute malnutrition.

Table 4 : Prevalence of nutritional status using nutritional indicators

\begin{tabular}{|c|c|c|c|c|}
\hline \multirow[t]{2}{*}{ Nutritional Indicators } & $\begin{array}{c}\text { Total } \\
\text { Population } \\
(\mathbf{N}=\mathbf{1 8 4})\end{array}$ & Girls $(N=94)$ & Boys $(\mathrm{N}=90)$ & $p$ \\
\hline & \multicolumn{4}{|c|}{ Prevalence $(\%)$} \\
\hline \multicolumn{5}{|l|}{ Height-for-age Z-score } \\
\hline Severe chronic denutrition $(Z<-3 \mathrm{SD})$ & 1.6 & 0 & 3.3 & S \\
\hline $\begin{array}{l}\text { Moderate chronic denutrition }(-3 \mathrm{SD} \leq \\
\mathrm{Z}<-2 \text { SD) }\end{array}$ & 11.4 & 8.5 & 14.4 & NS \\
\hline $\begin{array}{l}\text { Normal nutrition } \\
(-2 \mathrm{SD} \leq \mathrm{Z})\end{array}$ & 87 & 91.5 & 82.3 & NS \\
\hline \multicolumn{5}{|l|}{ BMI-for-age Z-score } \\
\hline $\begin{array}{l}\text { Severe acute denutrition } \\
(Z<-3 S D)\end{array}$ & 0.5 & 0 & 1.1 & NS \\
\hline $\begin{array}{l}\text { Moderate acute denutrition } \\
(-3 \mathrm{SD} \leq \mathrm{Z}<-2 \mathrm{SD})\end{array}$ & 8.7 & 5.3 & 12.2 & NS \\
\hline $\begin{array}{l}\text { Normal nutrition } \\
(-1 \mathrm{SD} \leq \mathrm{Z}<+2 \mathrm{SD})\end{array}$ & 90.2 & 93.6 & 86.7 & NS \\
\hline $\begin{array}{l}\text { Acute over-nutrition } \\
(+2 \mathrm{SD} \leq \mathrm{Z})\end{array}$ & 0.5 & 1.1 & 0 & NS \\
\hline
\end{tabular}

$\mathbf{N}$ : Total number of adolescents, $\boldsymbol{p}:$ threshold of significance,

NS : Non significant, S : Significant, SD : Standard deviation

In terms of household size, all nutritional status groups were represented in the group of adolescents in household larger than 5 children. In addition, severe chronic undernutrition, severe acute malnutrition and moderate acute malnutrition were not recorded in adolescents belonging to households up to and including 5 children.

Finally, among adolescents with a rank higher than 4 children in the siblings, all classes of nutritional status were present, while among those with a rank of less than or equal to 4 children, severe chronic undernutrition and severe acute malnutrition have been absent. The socio-demographic parameters of the study population do not have a remarkable impact on adolescents' nutritional status.

Table 5 : Adolescents' nutritional status in relation to their socio-demographic caracteristic

\begin{tabular}{lllllll}
\hline \multirow{2}{*}{$\begin{array}{l}\text { Socio-demographic } \\
\text { parameters }\end{array}$} & \multicolumn{2}{c}{ Height-for-age Z-Score } & \multicolumn{3}{c}{ BMI-for-age Z-Score } \\
& SCD & MCD & N1NS & SAD & MAD & N2NS $^{2}$ \\
\cline { 2 - 7 } & \multicolumn{5}{c}{ n (\%) } \\
\hline Total population & $3(1.6)$ & $21(11.4)$ & $160(87)$ & $1(0.5)$ & $16(8.7)$ & $167(90.8)$ \\
\hline $\begin{array}{l}\text { Father's education } \\
\text { background }\end{array}$ & & & & & \\
Non educated & $0(0)$ & $6(3.3)$ & $32(17.4)$ & $0(0)$ & $6(3.3)$ & $33(17.9)$ \\
Educated & $3(1.6)$ & $15(8.1)$ & $128(69.6)$ & $1(0.5)$ & $10(5.4)$ & $134(72.8)$ \\
\hline
\end{tabular}

Father's professional status 


\begin{tabular}{lllllll} 
Without fixed income & $1(0.5)$ & $6(3.3)$ & $49(26.6)$ & $0(0)$ & $4(2.2)$ & $52(28.3)$ \\
With fixed income & $2(1.1)$ & $15(8.1)$ & $111(60.3)$ & $1(0.5)$ & $12(6.5)$ & $115(62.5)$ \\
\hline $\begin{array}{l}\text { Size of the household } \\
\leq 5\end{array}$ & $0(0)$ & $2(1.1)$ & $17(9.2)$ & $0(0)$ & $0(0)$ & $19(10.3)$ \\
$>5$ & $3(1.6)$ & $19(10.3)$ & $143(77.7)$ & $1(0.5)$ & $16(8.7)$ & $148(80.4)$ \\
\hline Rank in siblings & & & & & & \\
$\leq 4$ & $0(0)$ & $5(2.7)$ & $53(28.8)$ & $0(0)$ & $1(0.5)$ & $57(31)$ \\
$>4$ & $3(1.6)$ & $16(8.7)$ & $107(58.2)$ & $1(0.5)$ & $15(8.2)$ & $110(59.8)$ \\
\hline
\end{tabular}

SCD : Severe chronic denutrition, MCD : Moderate chronic denutrition,

NiN S : Normal Nutritional (chronic) status, SAD : Severe acute denutrition,

MAD : Moderate acute denutrition, $\mathbf{N}_{2} \mathbf{N} \mathbf{S}$ : Normal Nutritional (acute) status,

$\mathbf{n}$ : Number of adolescents for each nutritional status

\section{Discussion}

The evaluation of the stature and weight status of adolescents attending the secondary schools 1 and 2 of Gagnoa (Côte d'Ivoire) showed various values of anthropometric indices. The mean value of the size-for-age $\mathrm{Z}$-score index is equal to $-0.8 \pm 0.1 \mathrm{SD}$ and that of the BMI-for-age Z-score index is equal to $-0.2 \pm 0.1 \mathrm{SD}$. In this population, $82.1 \%$ of individuals have a sizefor-age Z-score less than +0 SD and $53.8 \%$ of individuals have a BMI-forage Z-score less than $+0 \mathrm{SD}$. The prevalence of stunting (stunting) is $13 \%$, that of thinness is $8.7 \%$ and the prevalence of overweight and obesity are respectively $7.6 \%$ and $0.5 \%$. These results suggest that adolescents in this study have a body fat deficiency when compared to the reference population. According to the WHO (2007), different categories of individuals can be determined in a population according to their body size (Khadilkar et al., 2009). A subject with a size-for-age Z-score index below -2 SD is in short stature. The normal size one is the one whose $\mathrm{Z}$-score for the size-for-age index is higher than or equal to $-2 \mathrm{SD}$. A subject is found to be underweight when its BMI-for-age Z-score index is below $-2 \mathrm{SD}$. The overweight indicator is indicated for a subject with a BMI-for-age Z-score index higher than +1 SD and the subject with a Z-score BMI-for-age higher than +2 SD is obese (Waterlow et al., 1977; WHO, 1978; Hamill et al., 1979; De Onis and Habicht, 1996).

In view of the results obtained, this deficiency of corpulence is characterized by statural deficincy and underweight. However, a low risk of overweight that could evolve to increase the prevalence of obesity is noteworthy. These results corroborate those of Yapi et al. (2005) and those of Bléyéré et al. (2013) who found the presence of stature deficiency (stunting) and underweight (thinness) in adolescents in the region of Agnéby and children in the city of Abidjan (Côte d'Ivoire). However, the prevalence of statural insufficiency (13\%) among adolescents attending the secondary schools 1 and 2 of Gagnoa is low compared to that reported in the work of Yapi et al (2005) who recorded a prevalence of 27, 2\% in Agnéby and well 
above that of Bléyéré et al. (2013) which was 5.8\% in the city of Abidjan. On the contrary, the prevalence of thinness $(8.7 \%)$ from our results is low compared to that revealed by the studies of Yapi et al. in 2005 (29.6\%). This prevalence of underweight is closer to that of Bléyéré et al. obtained in 2013 in three primary schools in the city of Abidjan which was $12.5 \%$. Compared with the WHO reference population (Butte et al., 2007), the age-size and ageBMI Z-scores values of adolescent (girls) in this study are lower than the values of the -size-for-age and BMI-for-age Z-scores of adolescents of the same age. Our study showed an average size-for-age Z-score of $-0.5 \pm 0.1 \mathrm{SD}$ in girls while it was $-1.1 \pm 0.1 \mathrm{SD}$ in boys. The mean BMI-for-age Z-score in girls is $0.0 \pm 0.1 \mathrm{SD}$ versus $-0.5 \pm 0.1 \mathrm{SD}$ in boys. The prevalence of stature deficiency among boys $(17.8 \%)$ is twice higher than girls $(8.5 \%)$. As for the prevalence of underweight among boys, it is estimated to $13.3 \%$ while that of girls is $5.3 \%$. Boys are significantly more affected by body weight deficit than girls. Stature deficiency is more prevalent in boys than girls like the works of Sbaibi and Aboussaleh (2011), which demonstrated a proportion of statural insufficiency of $12.1 \%$ in adolescents compared to $4,9 \%$ of girls. These same authors revealed an underweight prevalence of $16.2 \%$ in boys against $4.9 \%$ among girls.

Differences between the prevalence of stature deficiency $(23.8 \%$ for boys versus $4.8 \%$ for girls) and leanness (4.8\% for boys versus $2.4 \%$ for girls) were revealed by studies in Nigeria (Ejike et al., 2010). With regard to the anthropometric evaluation of the nutritional status of adolescents in Gagnoa secondary schools 1 and 2, this study showed a presence of malnutrition in this population. In fact, $1.6 \%$ of severe chronic undernutrition was found among the total population with $3.3 \%$ of boys and zero prevalence among girls. Moderate chronic undernutrition affects respectively $14.4 \%$ of boys and $8.5 \%$ of girls. As for severe acute malnutrition was represented by $0.5 \%$ of the subjects in the study and by $1.1 \%$ in boys. As for moderate acute undernutrition, it was represented by $8.7 \%$ in all subjects, by $12.2 \%$ of boys and by $5.3 \%$ of girls. Finally, the prevalence of overnutrition was present at $0.5 \%$ for all the students and at $1.1 \%$ for girls. According to several authors, stunted, lean and obese subjects suffer from malnutrition (Waterlow et al., 1977; WHO, 1978; Hamill et al., 1979; De Onis and Habicht, 1996; Dorlencourt et al., 2000; Prista et al., 2003). These results show that all nutritional status classes exist in the adolescent population of Gagnoa secondary school 1 and 2. However, undernutrition is the most common form of malnutrition. Our work showed a prevalence of malnutrition lower than those of Yapi et al. (2005) who found $12.8 \%$ of severe chronic undernutrition, $14.4 \%$ of moderate chronic undernutrition, $12.8 \%$ of severe acute malnutrition and $16.8 \%$ of moderate acute malnutrition. Our results corroborate those of Bléyéré et al. (2013) who revealed the existence of all nutritional status classes 
in the student population of three primary schools in Abidjan. During their investigation, Bléyéré et al. (2013) reported $1.2 \%$ of severe chronic undernutrition, $4.6 \%$ of moderate chronic undernutrition, $5 \%$ of severe acute malnutrition, $7.5 \%$ of moderate acute malnutrition and $1.7 \%$ of overweight among preadolescents aged between 9 to 11 years. These results are different from those of Muthuri et al. (2014) who highlighted a shift from undernutrition to overnutrition in about $25 \%$ of adolescents from selected countries in eastern, southern and central sub-Saharan Africa.

In this study, students who show signs of malnutrition are of various socio-demographic classes. Malnutrition is present both in families of parents with fixed income and in families where the father is hasn't been educated and has no fixed income. In addition, some subjects from families with fewer than 5 children as well as subjects with fewer than 4 siblings show signs of malnutrition. These results show that the different socio-demographic situations presented in this study had no influence on the nutritional status of the study population. Unlike our results, Dapi et al. (2009) showed that the prevalence of stature deficiency $(12 \%, 6 \%$ and $5 \%$ respectively for total female and male populations) and underweight (3\%, 4\% and $1 \%$ respectively for total female and male populations) were higher in adolescents with poor and average socio-economic status compared to those in good socio-economic status respectively. In addition, Navti et al. (2014) found in studies in Cameroon that adolescents of good socio-economic status (64.1\%) are more affected by obesity caused by overnutrition than those of poor family $(10.1 \%)$.

\section{Conclusion}

The study of the stature and weight status revealed $13 \%$ of stature deficiency, $8.7 \%$ of underweight, $7.6 \%$ of risk of overweight and $0.5 \%$ of obesity among students in schools 1 and 2 of Gagnoa (Côte d'Ivoire). This population seems to be unaffected by the problem of obesity. However, results revealed that students are undernourished. At this level, 1.6\% of the study population suffer from severe chronic undernutrition, $11.4 \%$ from moderate chronic undernutrition, $0.5 \%$ are in severe acute malnutrition and $8.7 \%$ in moderate acute malnutrition. In addition, the education background, the employment status of fathers and also the size of the household and the rank in the siblings did not have any significant influence on the stature and weight status of the students attending these schools.

\section{Acknowledgement}

We particularly thank the managers of the secondary schools 1 and 2 of Gagnoa and also the medical team of the Hospital of Gagnoa for their support in collecting the data for this study. 


\section{References:}

1. Anonymous, 2015. L'état de l'insécurité alimentaire dans le monde 2015. Objectifs internationaux 2015 de réduction de la faim : des progrès inégaux. Rome, FAO: $46 \mathrm{p}$

2. Armitage, P. and Berry, G. (1987). Statistical methods in medical research, $2^{\text {nd }}$ edition, Oxford U.K., Blackwell Scientific Publications, 559 p.

3. Bléyéré, N. M., Kokoré, A. B., Konan, B. A. and Yapo, A. P. (2013). Prevalence of Child Malnutrition through their anthropométric indices in School Canteen of Abidjan. Pak J Nutr, 12 (1), 60-70.

4. Box. G. E. P. and Cox, D. R. (1964). An analysis of transformations. $J$ $R$ Stat Soc Series B (Method), 26 (2), 211- 252.

5. Butte, N. F., Garza, C. and De Onis, M. (2007). Evaluation of the feasibility of international growth standards for school-aged children and adolescents. $J$ Nutr, 137, 153-57.

6. Cogill, B. (2003). Anthropometric indicators measurement guide. Food and Nutrition Technical Assistance Project, Academy for Educational Development, Washington, D.C. 358p.

7. Cole, T. J., Flegal, K. M., Nicholls, D. and Jackson, A. A. (2007). Body mass index cut offs to defense thinness in children and adolescents: international survey. BMJ, 335 (7612), 194-197.

8. Collins, S. and Myatt, M. (2000). Short-term prognosis in severe adult and adolescent malnutrition during famine: use of a simple prognostic model based on counting clinical signs. JAMA, 284, 621- 626.

9. Dapi, L. N., Janlert, U., Nouedoui, C., Stenlund, H. and Haglin, L. (2009). Socioeconomic and gender differences in adolescents' nutritional status in urban Cameroon, Africa. Nutr Res, 29, 313-319.

10. De Onis, M. and Habicht, J. P. (1996). Anthropemetric reference data for international use: recommendations from a World Health Organization Expert Committee Am J Clin Nutr, 64, 650- 658.

11. De Onis, M., Onyango, A. W., Borghi, E., Siyam, A., Nishida, C. and Siekmann, J. (2007). Development of a WHO growth reference for school- aged children and adolescents. Bull WHO, 85, 660- 667.

12. Dorlencourt, F., Priem, V. and Legros, D. (2000). Indices anthropométriques utilisés pour le diagnostic de la malnutrition chez les adolescents et les adultes : bilan d'une revue de la littérature. Bull Soc Pathol Exot, 93 (5), 321-324.

13. Ejike, C. E. C. C., Ugwu, C. E. and Ezeanyika, L. U. S. (2010). Physical Growth and Nutritional Status of a Cohort of Semi-Urban Nigerian Adolescents. Pak J Nutr, 9 (4), 392-397.

14. Flegal, K. M. and Cole, T. J. (2013). Construction of LMS parameters for the Centers for Disease Control and Prevention 2000 growth charts. 
National health statistics reports, no 63. Hyattsville, MD: Natl Health Stat Report, 63, 1-3.

15. Garenne, M. (2014). Les indicateurs anthropométriques pour évaluer l'état nutritionnel des individus et des populations ; Working paper Development indicators, $27 \mathrm{p}$.

16. Hamill, P. V., Drizd, T. A., Johnson, C. L., Reed R. B. and Roche A. F. (1979). Physical growth: National Center for Health Statistics percentiles. Am J Clin Nutr, 32, 607-629.

17. Khadilkar, V. V., Khadilkar, A. V., Cole, T. J. and Sayyad, M. G. (2009). Cross sectional growth curves for height, weight and body mass index for affluent Indian children, 2007. Indian Pediatr; 46, 477489.

18. Latham, M. C. and Cobos, F. (1971). The effects of malnutrition on intellectual development and learning. Am J Public Health, 61 (7), 1307-1324.

19. Muthuri, S. K., Francis, C. E., Wachira, L-J. M., LeBlanc, A. G. and Sampson, M. (2014). Evidence of an Overweight/Obesity Transition among School-Aged Children and Youth in Sub-Saharan Africa: A Systematic Review. PLoS ONE, 9 (3), e92846. doi :10.1371/journal. Pone.0092846.

20. Navti, L. K., Ferrari, U., Tange, E., Pozza, S. B. D. and Parhofer, K. G. (2014). Contribution of socioeconomic status, stature and birth weight to obesity in Sub-Saharan Africa: cross-sectional data from primary school-age children in Cameroon. BMC Public Health, 14, 320-328.

21. Organisation Mondiale de la Santé [OMS] (2007). Growth reference 5-19 years: height-for-age (5-19 years), BMI-for-age (5-19 years). Disponible sur https: // www. Who. int/ growth ref/ who 2007- heightfor-age, bmi-for-age /en/. Consulté le 06 mai 2017.

22. Prista, A., Maia, J. A. R., Damasceno, A. and Beunen, G. (2003). Anthropometric indicators of nutritional status: implications for fitness, activity, and health in school-age children and adolescents from Maputo, Mozambique. Am J Clin Nutr, 77, 952-959.

23. Rodríguez, L. S., Bernis, C. C. and Montero, L. P. (2010). Utilisation des nouveaux standards de croissance de l'OMS pour le diagnostic du surpoids chez les enfants de Madrid. Antropo, 22, 1-10.

24. Sbaibi, R. and Aboussaleh, Y. (2011). Étude exploratoire de l'état staturo-pondéral des enfants collégiens dans la commune rurale Sidi El Kamel au Nord-Ouest Marocain. Antropo, 24, 61-66.

25. Singh, M. (2004). Role of Micronutrients for Physical Growth and Mental Development. Indian J Pediatr; 71 (1), 59-62. 
26. Wamba, P. C. F., Oben, J. E., and Cianflone, K. (2013). Prevalence of Overweight, Obesity, and Thinness in Cameroon Urban Children and $\begin{array}{lllll}\text { Adolescents. } J \quad \text { Obes, } & J \text { ID } & \text { 737592, } & \text { 9p. }\end{array}$ http://dx.doi.org/10.1155/2013/737592:

27. Waterlow, J. C. (1992). Assessment of nutritional status in the community. In: Protein Energy Malnutrition London, Edward Arnold, pp 212- 228.

28. Waterlow, J. C., Buzina, R., Keller, W., Lane, J. M., Nichaman, M. Z. and Tanner, J. M. (1977). The presentation and use of height and weight data for comparing the nutritional status of groups of children under the age of 10 years. Bull WHO, 55 (4), 489-498.

29. WHO (1978). A Growth chart for International Use in Maternal and Child Health Care. Guidelines for Primary Health Care Personnel. Geneva: World Health Organization (WHO), 36 p.

30. WHO (1983). Measuring change in nutritional status. Guidelines for assessing the nutritional impact of supplementary feeding programs for vulnerable groups. Geneva, $61 \mathrm{p}$.

31. WHO (2000). Turning the tide of malnutrition: responding to the challenge of the 21st century. Geneva :(WHO/NHD/00.7), $20 \mathrm{p}$.

32. Yapi, H. F., Ahiboh, H., Monnet, D. and Yapo, A. E. (2005). Parasites intestinaux, profil hématologique et statut anthropométrique de l'enfant scolarisé en Côte d'Ivoire. Cahiers Santé, 15 (4), 17- 21. 